\title{
Improving the process and outcome of care in COPD: development of a standardised assessment tool
}

\author{
Paul Jones', Gale Harding ${ }^{b}$, Ingela Wiklund', Pamela Berry', Nancy Leidy \\ a Department of Cardiac and Vascular Sciences, St. George's Hospital, University of London, London, UK \\ ${ }^{b}$ Center for Health Outcomes Research, United BioSource Corporation, Maryland, USA \\ c GlaxoSmithKline, Middlesex, UK
}

Received 16th March 2009; revised version received 2nd July 2009; accepted 12th July 2009; online 18th August 2009

\begin{abstract}
Introduction: A major goal of COPD treatment is to reduce symptom burden and ensure that the patient's health is as good as possible. This goal requires regular systematic assessment of the patient's COPD with clear and efficient communication between the patient and clinician.

Aim: To explore patient and physician descriptions of COPD attributes, in order to inform content development of a patient-reported clinical assessment tool.

Methods: Qualitative research methods (one-to-one interviews and patient focus groups) were used to elicit key characteristics to evaluate COPD health status and explore how patients with COPD experience their condition. ATLAS.ti version 5.0 was used to identify major themes and generate an item pool.

Results: Fifty-eight patients with COPD (GOLD stages 1-4; MRC grades 2-5) and 10 clinicians participated in this research. Twenty-one items were generated, capturing patient assessment of breathlessness, wheeze, cough, sleep, activity limitation, energy/fatigue, social function, and anxiety.

Conclusions: This qualitative study identified a broad range of items that are potentially suitable for inclusion in a short, simple COPD assessment tool for use in routine clinical practice.

(C) 2009 General Practice Airways Group. All rights reserved.

P Jones, et al. Prim Care Resp J 2009; 18(3): 208-215

doi:10.4104/pcrj.2009.00053
\end{abstract}

Keywords chronic obstructive pulmonary disease (COPD), optimal management, health status assessment, questionnaire, chronic bronchitis

\section{Introduction}

Chronic obstructive pulmonary disease (COPD) is a leading cause of morbidity and mortality, affecting $9-10 \%$ of all adults over 40 years of age. ${ }^{1,2}$ The World Health Organisation (WHO) estimates that by 2020 COPD will be the third-leading cause of death and fifth-leading cause of disability worldwide. ${ }^{3}$

COPD is not fully reversible with treatment and is usually progressive. ${ }^{4} \mathrm{~A}$ major goal of treatment is to ensure that the patient's level of health is optimised, i.e., that it is as good as possible for the individual's level of disease severity. The Global Initiative for Chronic Obstructive Lung Disease (GOLD) and organisations such as the American Thoracic Society
(ATS) and European Respiratory Society (ERS) have all published recommendations to facilitate COPD diagnosis and to guide disease management. ${ }^{4-6}$ Despite the existence of these guidelines, there is evidence to suggest that a substantial proportion of patients are not achieving the level of treatment success that may be possible. ${ }^{7-9}$ In addition, many patients experience medical emergencies and hospitalisations, work absenteeism and activity limitation. These events may have significant physical and emotional impacts on patients and their carers ${ }^{8}$ and result in a high economic burden to society. ${ }^{10,11}$

Whilst guidelines emphasise the use of spirometry for

* Corresponding author: Professor Paul Jones, Department of Cardiac and Vascular Sciences, St. George's, University of London, Cranmer Terrace, London, SW17 ORE, UK. Tel: +44 02086729944 Fax: +44 02087255955 E-mail: pjones@sgul.ac.uk 
diagnosis of COPD and determination of disease severity, lung function testing alone does not provide a measurement of the overall impact of COPD on health status and is not generally available in primary care where the majority of patients are routinely treated. ${ }^{4}$ A critical step in ensuring that diagnosed patients are optimally managed is gathering reliable and valid assessment data from the patient - such as daily symptoms, activity limitation, and other manifestations of disease. A standardised clinical assessment tool that patients can complete across key dimensions of COPD health could facilitate communication between the patient and clinician, serve as a focal point for the development and evaluation of attainable treatment goals, and improve the process and outcome of care. Existing health status measures such as the St George's Respiratory Questionnaire (SGRQ) ${ }^{12}$ and the Chronic Respiratory Disease Questionnaire $(\mathrm{CRQ})^{13}$ - while reliable, valid, and useful for clinical trials - are lengthy, with scoring algorithms less than ideal for routine use in clinical practice. Even the shorter Clinical COPD Questionnaire $(\mathrm{CCQ})^{14}$ is longer than may be applicable in routine practice.

Recent assessment questionnaire development work by Bailey and colleagues ${ }^{15}$ aimed to build on the success of the Asthma Control Test ${ }^{16}$ and focussed on the concept of COPD stability. It also included the patient's sense of control over their disease. This work confirmed the feasibility of developing a short patient-completed tool for COPD patients but identified methodological problems with the initial attempt (the COPD-AQ) which limited its validity. ${ }^{15}$ Learning from this, we aim to develop a new patient-completed disease-specific clinical assessment tool which is short (the aim is for 5 - 7 items) and designed for use by both patients and physicians. It should provide a standardised, reliable and valid measure of overall COPD health status that will aid clinical assessment of the patient to help inform the development of treatment goals and help COPD patients achieve their optimal health status. This paper describes the initial development of the pool of items for this instrument to be called the COPD Assessment Test (CAT).

\section{Methods \\ Overview}

The development process used to identify items for the COPD assessment test evolved in three stages. First, a strategic review of the literature was conducted to confirm the need for such a tool and to provide background on defining the concept to be measured. The need for a simple assessment tool was agreed on by an international panel of experts in pulmonary and primary care. This panel also agreed that the concept of an optimised state had clinical utility: that achievement of the best possible health - given the patient's underlying COPD severity - was an appropriate and realistic management aim. Second, telephone interviews were conducted with practising physicians to test the concept of optimising the patient's health state and to identify indicators that clinicians use to determine that a change in treatment is advised or that the goal of optimisation has been achieved. Information gained from the first two stages was used to guide the third, which took the form of a series of qualitative research studies (patient one-to-one interviews and focus groups) to determine how patients with COPD experience their condition and the language they use to describe it. Key concepts that were meaningful and important to patients were identified, and a pool of items for potential inclusion in the assessment tool was developed based on these interviews. The item pool was also reviewed by the expert panel to ensure all identified concepts were included.

\section{Literature review}

A review of the literature was conducted to explore the information physicians currently use to assess whether or not a COPD patient is being "optimally" managed and to identify specific manifestations of COPD or tolerance levels used for clinical decision-making. The review focused on placebocontrolled studies conducted in this patient population and current guidelines for the treatment and management of COPD.

Variables used to assess patients in placebo-controlled trials consistently included (in addition to lung function): dyspnoea; chest tightness; severity and frequency of cough; difficulty in expectoration; sleep disturbance; exercise capacity; and the use of rescue medication. A number of clinical practice guidelines for the diagnosis and treatment of COPD also exist, based in large part on the evidence-based consensus guidelines published by the ATS/ERS, ${ }^{10}$ the British Thoracic Society (BTS), ${ }^{17}$ the National Institute for Health and Clinical Excellence (NICE) in the UK, ${ }^{18}$ and the Global Initiative for Chronic Obstructive Lung Disease (GOLD). ${ }^{4}$ These guidelines are consistent in their emphasis that the approach to managing "stable" COPD should be individualised to address symptoms - particularly dyspnoea, cough, sputum, and exercise tolerance. We found, however, that whilst the literature provided a foundation for symptom indicators of COPD health state, even treatment guidelines provided no definition of the limits of variability for COPD symptoms or manifestations of this condition which should trigger a change in patient management. In addition, we found no simple, short measure of overall COPD severity based upon patients' experience of the disease - that could be used in routine practice, although we recognise that the CCQ has been used quite extensively in general practice for this purpose.

Questionnaire development and expert panel review A panel comprised of international experts in pulmonary disease from both primary and specialist care considered the 
results of the literature review and discussed the concept of optimisation, the role of the COPD assessment tool, and the best measurement approach. At a later stage of the development process, the expert panel also reviewed the findings from qualitative interview and focus groups used to generate the key concepts and the pool of items which would comprise the content of this new instrument.

\section{Physician interviews}

An interview guide was developed to gain insight from physicians about their experience of COPD patients with a range of disease severity, and what criteria they used to help them make clinical decisions with respect to patient treatment and management. Individual telephone interviews were then conducted with a small sample of primary care physicians and pulmonologists in April and May 2008 to ensure that the COPD assessment tool being developed was clinically relevant to monitor patient COPD status. Clinicians were identified through Centerwatch sites (http://www.centerwatch.com), and were eligible to participate if they spent at least $50 \%$ of their time in clinical practice. Specifically, physicians were asked to describe the key characteristics (or signs and symptoms) they assess during a routine clinic visit to determine if a patient's COPD health is optimised - i.e., a COPD patient whose health status was "the best that it can be" relative to the severity of their lung damage and for which no change or adjustment in therapy could be offered. They were then asked to describe the signs and symptoms of a COPD patient who was exacerbation-free but had room for improvement from additional interventiontreatment or otherwise. They were also asked what information or questions they ask in routine assessment of their COPD patients. Interviews were audio-recorded and transcribed. The physicians were paid an honorarium for their participation. A content analysis approach was used to generate general themes and specific issues related to the assessment of COPD health status from these transcripts and from field notes.

\section{Patient interviews}

A semi-structured interview guide for use with patients was developed from the results of the literature review and physician interviews. Structured one-to-one qualitative interviews and focus group discussions were then conducted in the USA and UK between January and July 2008 by experienced interviewers. Eight telephone interviews and five focus groups were conducted in the USA, with patients recruited from three pulmonary clinics located in: San Diego, CA; Spartanburg, SC; and Waterbury, CT. Two focus groups were conducted in the UK at St George's Hospital, University of London. Ethical committee approval was obtained for each participating centre prior to study initiation. Patients provided written consent before participating in the study and were compensated for their time on completion of the interview or focus group session.

To participate, patients had to be between the ages of 40 and 80 years with a current diagnosis of COPD and disease severity defined by GOLD stages $1-4$. Patients with a primary diagnosis of asthma, with or without fixed obstruction, $\alpha-1$ antitrypsin deficiency as the underlying cause of COPD, known respiratory disorders other than COPD, a current diagnosis of organic heart disease with resultant left ventricular failure and NYHA class 2-4, COPD exacerbation within the last six weeks, known neuromuscular disease, or a simultaneous process that could result in significant dyspnoea independent of COPD, were excluded from the study. Separate focus group sessions were conducted with patients according to their severity.

To gather information on optimal COPD health, patients were asked to describe, from their own perspective, the symptoms they experience on a typical or usual day, a betterthan-usual day (i.e., "good" day), and a day worse than usual but not bad enough to seek medical assistance (i.e., "bad" day). For each type of day ("usual/typical", "good", or "bad"), they were also asked to describe the frequency and severity of symptoms and the impact these symptoms had on their daily lives. For analytical purposes, descriptions of "good" days were considered attributes of optimal COPD health. All sessions were audio-recorded and transcribed by one researcher.

Transcripts were coded in ATLAS.ti version 5.0 qualitative analysis software, and the data were examined for general themes and specific issues and concerns associated with the variability and predictability of COPD as described by the patients. Based on content analysis, an item pool was generated that captured the range of themes identified during qualitative interviews and focus groups. The expert panel reviewed the item pool to ensure that all previously identified concepts were included.

\section{Results}

\section{Physician interviews}

Eight primary care physicians and two pulmonologists participated in the interviews. Clinicians spent between $50-100 \%$ of their time in clinical practice and saw at least 15 or more COPD patients per month. Content analysis of physician interviews indicated that COPD patients whose health status was optimal, or the best that it could be for a given disease severity, would be characterised as follows: 1) symptoms controlled (i.e., stable and not a source of major complaint from the patient) $(n=7) ; 2)$ activities of daily living unaffected $(n=6) ; 3)$ rescue medications not used or used infrequently $(n=5)$; 4) patient exercised $(n=5)$ and took maintenance medications as prescribed $(n=4)$; and 5) 
pulmonary tests remained stable $(n=2)$. Conversely, those whose COPD health could be improved were characterised as: complaining about symptoms (i.e., increased breathlessness, cough, sputum production); unable to complete or having difficulty completing usual daily activities; and increased use of rescue medication. Physicians also reported that they used patient-reported symptoms and visible assessments of the patients' respiratory difficulty.

Lung function tests were also considered by five of the physicians, although several mentioned that these tests did not present a complete picture of patient health. Five physicians reported comparing the overall symptom levels against a previous visit or baseline status. Whilst all 10 physicians considered the frequency and severity of symptoms to be important, they differed in how much weight they gave to each symptom type. In general, they trusted that patients were able to recognise acute change in their health with the onset of an exacerbation, as opposed to gradual increases in symptom frequency and severity which suggested a general decline in health.

The results of physician interviews provided preliminary evidence of key indicators of COPD health and converged with factors cited in the reviewed literature, including dyspnoea, sputum production, cough, activity limitation, fatigue, and use of rescue medication. It was clear, however, that there is no standardised measure used by physicians to assess their patients' COPD health.

\section{Patient interviews}

Qualitative data were gathered from 58 patients with COPD, at which point there was evidence of saturation (i.e., no new information was gleaned from interviewing further subjects). Fifty patients participated in one of seven focus group discussions conducted in the USA ( $n=36$; five focus groups) or the UK ( $n=14$; two focus groups), and eight patients participated in one-to-one interviews. Patients included GOLD stages 1-4 and MRC grades 2-5. The demographic and clinical characteristics of the participating patients are given in Tables 1 and 2. Qualitative findings were similar between USA and UK patients groups, so the data were pooled.

Terms used to describe symptoms of COPD were generally found to be consistent across patients, regardless of severity level. Typical symptoms included shortness of breath, chest tightness, and cough with or without sputum. Other reported symptoms were: wheezing; fatigue; weakness; anxiety; sleep disruption; and limitations in daily activities. A major concern for patients was their breathing, particularly how changes to their breathing can have an impact on their daily lives and emotional well-being. Findings from the interviews and focus groups indicate that patients can differentiate between a "usual/typical" day, a "good" and a "bad" day. The major themes and concepts that patients used to describe "good"
Table 1. Demographic characteristics of patient

qualitative interviews and focus groups.

\begin{tabular}{|c|c|c|c|}
\hline & $\begin{array}{l}\text { US Focus } \\
\text { Group } \\
(n=36)\end{array}$ & $\begin{array}{l}\text { UK Focus } \\
\text { Group } \\
(n=14)\end{array}$ & $\begin{array}{l}\text { Interviews } \\
\quad(n=8)\end{array}$ \\
\hline Age (Year, Mean (SD)) & $62.8(7.8)$ & $68.6(8.0)$ & $61.1(9.1)$ \\
\hline \multicolumn{4}{|l|}{ Gender } \\
\hline Male & $19(52.8 \%)$ & $10(71.4 \%)$ & $7(87.5 \%)$ \\
\hline Female & $17(47.2 \%)$ & $4(28.6 \%)$ & $1(12.5 \%)$ \\
\hline \multicolumn{4}{|l|}{ Race/ethnicity* } \\
\hline Black/African American & $5(13.9 \%)$ & & $1(12.5 \%)$ \\
\hline White & $30(83.3 \%)$ & $14(100 \%)$ & $7(87.5 \%)$ \\
\hline Other $^{1}$ & $1(2.8 \%)$ & & \\
\hline \multicolumn{4}{|l|}{ Employment status } \\
\hline Employed, full-time & $4(11.1 \%)$ & $1(7.1 \%)$ & $2(25.0 \%)$ \\
\hline \multicolumn{4}{|l|}{ Employed, part-time } \\
\hline \multicolumn{4}{|l|}{ Homemaker } \\
\hline Retired & $15(41.7 \%)$ & $11(78.6 \%)$ & $2(25.0 \%)$ \\
\hline Unemployed & & $1(7.1 \%)$ & \\
\hline Disabled $x$ & $12(33.3 \%)$ & $1(7.1 \%)$ & $4(50.0 \%)$ \\
\hline \multicolumn{4}{|l|}{ Highest level of education } \\
\hline No formal qualifications & & $5(35.7 \%)$ & \\
\hline Less than high school & $3(8.3 \%)$ & & $1(12.5 \%)$ \\
\hline High school & $17(47.2 \%)$ & & $5(62.5 \%)$ \\
\hline \multicolumn{2}{|l|}{ GCSE/O' levels or equivalent } & $2(14.3 \%)$ & \\
\hline \multicolumn{2}{|l|}{$\mathrm{A}^{\prime}$ levels or equivalent } & $4(28.6 \%)$ & \\
\hline \multicolumn{4}{|c|}{$\begin{array}{l}\text { Associate degree/technical/ } \\
\text { trade school/vocational or } \\
\text { work-based }\end{array}$} \\
\hline College & $5(13.9 \%)$ & & \\
\hline Graduate school & $2(5.6 \%)$ & & \\
\hline Other $^{2}$ & $1(2.8 \%)$ & $1(7.1 \%)$ & \\
\hline \multicolumn{4}{|l|}{ Smoking status } \\
\hline Current smoker & $16(44.4 \%)$ & $4(28.6 \%)$ & $4(50.0 \%)$ \\
\hline Ex-smoker & $20(55.6 \%)$ & $10(71.4 \%)$ & $4(50.0 \%)$ \\
\hline
\end{tabular}

and "bad" days, along with sample quotations, are included in Table 3.

On "good" days, patients across all of the severity groups described a reduction in their symptoms - breathing and coughing being the most frequently reported symptoms to improve. Other improvements included higher energy level, less wheezing, chest tightness and tiredness, and better sleep. They also indicated that they used their rescue medications less, were more physically active, and felt better emotionally. Conversely, on "bad" days, they described shortness of breath, worsening of cough and wheezing, loss of energy, 
P Jones et al.

Table 2. Clinical characteristics of patient qualitative interviews and focus groups.

\begin{tabular}{|c|c|c|c|}
\hline & $\begin{array}{l}\text { US Focus Group } \\
\qquad(n=36)\end{array}$ & $\begin{array}{l}\text { UK Focus Group } \\
\qquad(n=14)\end{array}$ & $\begin{array}{l}\text { Interviews } \\
\quad(n=8)\end{array}$ \\
\hline \multicolumn{4}{|l|}{ Pulmonary Diagnosis } \\
\hline \multicolumn{4}{|l|}{ Overall pulmonary disease severity based on GOLD stage, $\mathrm{N}(\%)$} \\
\hline GOLD-1 mild COPD & $1(2.8 \%)$ & & \\
\hline GOLD-2 moderate COPD & $19(52.8 \%)$ & $5(35.7 \%)$ & $4(50.0 \%)$ \\
\hline GOLD-3 severe COPD & $11(30.6 \%)$ & $5(35.7 \%)$ & $2(25.0 \%)$ \\
\hline GOLD-4 very severe COPD & $5(13.9 \%)$ & $4(28.6 \%)$ & $2(25.0 \%)$ \\
\hline \multicolumn{4}{|l|}{ MRC dyspnoea grade (how breathless this patient is), N (\%) } \\
\hline No breathlessness except with strenuous exercise & & & $2(25.0 \%)$ \\
\hline Breathlessness when hurrying on the level or walking slightly uphill & $5(13.9 \%)$ & & \\
\hline Walks slower than people of the same age on the level & $12(33.3 \%)$ & $7(50.0 \%)$ & $2(25.0 \%)$ \\
\hline Stops for breath after walking about 100 yards or a few minutes on the level & $16(44.4 \%)$ & $6(42.9 \%)$ & $4(50.0 \%)$ \\
\hline Too breathless to leave the house or breathless when dressing or undressing & $3(8.3 \%)$ & $1(7.1 \%)$ & \\
\hline \multicolumn{4}{|l|}{$\mathrm{FEV}_{1}(\mathrm{~L})$} \\
\hline $\mathrm{N}$ & 36 & 14 & 8 \\
\hline Mean (SD) & $1.5(0.6)$ & $1.0(0.4)$ & $1.6(0.6)$ \\
\hline Median & 1.6 & 1.1 & 1.7 \\
\hline Range & $(0.4-2.7)$ & $(0.6-1.7)$ & $(0.8-2.5)$ \\
\hline \multicolumn{4}{|l|}{$\mathrm{FEV}_{1} \%$ predicted $(\%)$} \\
\hline $\mathrm{N}$ & 20 & 14 & 8 \\
\hline Mean (SD) & $53.1(21.8)$ & $38.71(12.7)$ & $45.4(13.9)$ \\
\hline Median & 55.5 & 44.5 & 50.0 \\
\hline Range & $(12.0-129.0)$ & $(19.0-55.0)$ & $(23.0-62.0)$ \\
\hline \multicolumn{4}{|l|}{ FVC (L) } \\
\hline $\mathrm{N}$ & 36 & 14 & 8 \\
\hline Mean (SD) & $2.7(1.0)$ & $2.4(0.7)$ & $3.1(1.1)$ \\
\hline Median & 2.8 & 2.3 & 3.1 \\
\hline Range & $(0.4-4.8)$ & $(1.3-3.9)$ & $(1.6-4.6)$ \\
\hline \multicolumn{4}{|l|}{ FEF $25-75 \%(\%)$} \\
\hline $\mathrm{N}$ & 36 & & 8 \\
\hline Mean (SD) & $27.4(16.7)$ & & $19.9(5.5)$ \\
\hline Median & 25.5 & & 20.5 \\
\hline Range & & & $(11.0-28.0)$ \\
\hline \multicolumn{4}{|l|}{ Long-term oxygen therapy, $\mathrm{N}(\%)$} \\
\hline Yes & $5(14.3 \%)$ & $2(14.3 \%)$ & \\
\hline No & $30(85.7 \%)$ & $6(42.9 \%)$ & $8(100 \%)$ \\
\hline Missing & $1(2.8 \%)$ & $6(42.9 \%)$ & \\
\hline
\end{tabular}

and problems with sleep. Across all severity groups, patients reported that on "bad" days they would reduce their activity, opting to "rest" or "stay in bed" rather than seek help. On these days they had increased rescue medication use and feelings of fear, frustration, anxiety, and depression.

The frequency of good and bad days was variable both between and within patients. Most patients could not predict when they would have a day with worse symptoms, although many indicated that weather was definitely a factor. Of note, a number of patients described waking up with symptoms as an indicator of a "bad" day, indicating that they may be able to predict a "bad" day upon awakening.

The results of patient interviews and focus groups were used to develop a framework for understanding COPD health and the content and structure of a draft assessment tool. The physician interviews were used in the development of the interview guide for the qualitative patient research and also as a check to ensure that the concepts identified were comprehensive in the description of COPD.

\section{Item identification and expert panel review}

The qualitative research revealed a high level of convergence between the concepts and themes that patients and physicians identified (Table 4). It was therefore possible to develop a draft framework and 21 draft items representing key indicators of COPD health status which reflected this. Identified items include respiratory symptoms of dyspnoea, 
Table 3. Major themes and concepts elicited from patient qualitative interviews and focus groups.

\begin{tabular}{|c|c|}
\hline Major themes and concepts & Sample quotation \\
\hline $\begin{array}{l}\text { Usual/typical day } \\
\text { (Good days/bad days) }\end{array}$ & $\begin{array}{l}\text { - I'm not breathing hard, I can do what I want (good day) } \\
\text { - } \quad \text { You can tell, just when you wake up, how you feel }\end{array}$ \\
\hline Breathing & $\begin{array}{ll} & \text { I think it's just one word: breathlessness } \\
\text { - } \quad \text { I breath[e] easier, longer (good day) }\end{array}$ \\
\hline Chest tightness & $\begin{array}{ll}\text { - } & \text { My chest gets tighter } \\
\text { - } & \text { My chest starts hurting }\end{array}$ \\
\hline Wheeze & - $\quad$ Start wheezing more \\
\hline Cough & - I cannot stop coughing \\
\hline Energy/fatigue/tiredness & $\begin{array}{ll}- & \text { Sluggish, tired } \\
\text { - } & \text { On a bad day I feel tired }\end{array}$ \\
\hline Weakness & $\begin{array}{ll}- & \text { I was really weak } \\
\text { - } \quad \text { Your legs feel stronger (good day) }\end{array}$ \\
\hline Sleep quality & - When I lay down ... it just starts cutting my breath \\
\hline Appetite & - On a good day you have an appetite, on a bad day you don't care \\
\hline Daily activities $\&$ activity limitation & $\begin{array}{l}\text { - I feel good and I'm getting things accomplished (good day) } \\
\text { - } \quad \text { I . . . need quite a bit of time before I think I'm ready to go anywhere or do anything } \\
\text { - } \quad \text { Whenever I go anywhere, I plan before I go, rather than just go }\end{array}$ \\
\hline Social life & $\begin{array}{l}\text { - } \quad \text { No interest in calling people, or receiving phone calls } \\
\text { - } \quad \text { get quite embarrassed } \\
\text { - } \quad \text { You can laugh and talk and enjoy your company (good day) }\end{array}$ \\
\hline Feelings/emotions & $\begin{array}{ll}\text { - } & \text { It scares the heck out of me when I can't breath[e] } \\
\text { - } & \text { I feel more confident (good day) } \\
\text { - } \quad \text { I get really frustrated } \\
\text { - } \quad \text { I get really fed up with myself }\end{array}$ \\
\hline Rescue medication & - $\quad$ And I didn't have to use my Albuterol often (good day) \\
\hline
\end{tabular}

Table 4. Consensus of key indicators of COPD health status.

\begin{tabular}{lcc}
\hline Indicator & Patient & Physician \\
\hline Respiratory symptoms & $\mathrm{X}$ & $\mathrm{X}$ \\
Breathlessness & $\mathrm{X}$ & $\mathrm{X}$ \\
Chest tightness/pain & $\mathrm{X}$ & $\mathrm{X}$ \\
Cough & $\mathrm{X}$ & $\mathrm{X}$ \\
Sputum production & $\mathrm{X}$ & $\mathrm{X}$ \\
Wheeze & & $\mathrm{X}$ \\
\hline Systemic symptoms & $\mathrm{X}$ & \\
Energy/fatigue/weakness & $\mathrm{X}$ & $\mathrm{X}$ \\
Sleep disturbance & $\mathrm{X}$ & $\mathrm{X}$ \\
Appetite & & $\mathrm{X}$ \\
\hline Activity & $\mathrm{X}$ & \\
Exercise tolerance & $\mathrm{X}$ & \\
Social functioning & $\mathrm{X}$ & \\
Activity limitation & & \\
\hline Emotional health & $\mathrm{X}$ & \\
Anxiety/frustration & & \\
\hline Other & $\mathrm{X}$ & \\
Rescue medication use & & \\
& &
\end{tabular}

cough, sputum production and wheeze as well as systemic symptoms of fatigue and sleep disturbance. Additional indicators include limitations in daily activities, social life, emotional health, and rescue medication use. The principal criterion for inclusion was a clear indication from the patient interviews that the items were important to them. Findings from the literature review and physician interviews were used as supportive evidence. Appetite was excluded from the item pool because it was considered to be insufficiently specific to COPD. The items were presented to the expert panel members, who agreed that the framework and draft items were relevant, based on their experience. The panel agreed that, although a number of items could be considered redundant because of very similar content, differently worded items should be subjected to empirical testing in the next stage of the COPD assessment tool development.

\section{Discussion}

Our literature review identified the need for an assessment tool that can enhance and facilitate patient and physician communication in order to improve the clinical management of COPD. The qualitative interviews and focus groups with COPD patients and the interviews with community physicians found a clear convergence of agreement over the key indicators of COPD health. These indicators include: shortness of breath; cough; sputum production; wheeze; activity limitations; emotional well-being; sleep; energy/fatigue; and use of rescue medication. Whilst there was variation in the degree to which patients experienced these signs and symptoms, and the corresponding impact of each on a 
"good" versus "bad" day varied, these signs and symptoms were reported universally by all patients regardless of COPD severity. The indicators identified were very similar to findings from a large multinational study of over 1,000 patients with symptoms compatible with COPD in which the most frequently reported symptom was shortness of breath (78\%) and the most frequent complaint reported by patients was that "they could not complete the activities they like to do" (54\%) due to their COPD. ${ }^{19}$ The impact of COPD variability on activity levels also reflects the content of most health-related quality of life questionnaires which contain a domain measuring symptoms associated with daily activities (Chronic Respiratory Disease Questionnaire, $\mathrm{CRDQ}^{13}$ ) or the inability to carry out physical activities (St George's Respiratory Questionnaire, $\mathrm{SGRQ}^{12}$ ). Our results are also in agreement with the recent consensus document on outcomes in COPD ${ }^{20}$ in which shortness of breath and activity limitations were identified, along with lung function and hypoxemia, as factors related to adverse prognosis.

The most important outcome from this study is the item pool, which was derived directly from COPD patients and which will go forward to further testing for inclusion in the final tool (the COPD Assessment Test [CAT]). Thus, this instrument will meet one of the basic requirements for a patient-reported outcome (PRO). ${ }^{21}$ Whilst it has not been created as a primary outcome measure for use in clinical trials, it is being developed to the same standards. This is important, because PROs are now being introduced as part of the formal assessment of treatment programmes in health care systems - as evidenced by recent developments requiring mandatory reporting of PRO scores in selected specialties in the UK National Health Service. ${ }^{22}$

In developing this instrument, we drew on the experience of the team who produced the COPD-AQ, ${ }^{15}$ with whom we had links. We learnt of the difficulties of defining 'control' and 'stability' in COPD, so we began our development process from the concept of 'optimisation'. However, it became clear that whilst this was an excellent aim for disease management, the contribution of a patient-reported assessment instrument to the process of optimisation should be confined to the provision of a reliable assessment of the patient's health status. Other factors such as lung function and exacerbation frequency also need to be taken into account in managing COPD.

In contrast to the COPD-AQ development, we decided to ground our item generation process firmly on what patients said about COPD and the effect that it has upon them, rather than on the findings from a literature and questionnaire review. ${ }^{15}$ One of the striking findings of this study is the similarity of the items to those contained in health status and health-related quality of life instruments for COPD. The items derived from our patient interviews and illustrated in Table 4 show a richness that is often difficult to catch in its entirety in a final instrument, since the items must be applicable to every patient that may be assessed with the tool. Thus, the final instrument will be made up of a core group of items that can be used to assess every patient reliably and in the same way. In some ways, this is the difference between the "quality of life" of an individual, and "health status" as measured using a standard assessment instrument. We, the developers and committee of international experts in pulmonary disease, have been led totally by what our patients and physicians told us about important factors in COPD, and we have been struck by the observation that the items seem to form a health-related quality of life or health status instrument, albeit much simpler than complex questionnaires such as the SGRQ and CRQ.

Data to test the 21 items identified through this process are being collected in prospective studies that will identify the items with the best measurement properties and the best fit to a unidimensional model of impaired health status in COPD. The items identified by the item-reduction process will form the new instrument - the COPD Assessment Test (CAT). The target item number is 5-7, but the precise number will be determined by the criteria of achieving comprehensive coverage and reliable measurement properties - assessed by a range of statistical techniques. The number of items will be an important but secondary consideration. In addition, a series of studies is being carried out to test the validity of the new instrument in terms of its discriminative power (the ability to distinguish between different degrees of COPD severity), its evaluative power (ability to quantify change) in terms of sensitivity to changes in COPD severity and response to therapy, and its predictive ability (predicting future health events such as exacerbations and hospital admissions). A key aspect of these validation studies will be direct comparisons between the CAT and more complex instruments such as the CCQ and SGRQ - to test whether a simple, short instrument suitable for use in routine practice has measurement properties comparable to the more complex validated instruments currently available.

\section{Conclusion}

The objective of this study was to determine core items that reflect the full impact of COPD on patients. Twenty-one items were identified in a comprehensive qualitative study in COPD patients with a wide range of disease severity in two countries. The key themes identified by patients corresponded to factors identified in the literature review, and were supported by the physicians interviewed and the members of an expert panel. We are confident that the selected items reflect the range of symptomatic effects that COPD has on patients. The subsequent planned item-reduction process and 
prospective validation studies, will confirm whether it is possible to turn these items into a reliable health status instrument simple enough for routine clinical practice.

\section{Acknowledgements}

The development of the COPD Assessment Test (CAT) is supported by a grant from GlaxoSmithKline.

We would like to thank the COPD Assessment Test (CAT) working group members: Professor Alvar Agusti, Hospital Clinic, University of Barcelona, Barcelona, Spain Dr William Bailey, University of Alabama Lung Health Center, Birmingham,

Alabama, USA

Dr Otto Bauerle, Centro Medico Las Americas, Merida, Mexico

Dr David Halpin, Royal Devon \& Exeter Hospital, Exeter, UK

Professor Christine Jenkins, Woolcock Institute of Medical Research,

Camperdown NSW, Australia

Dr Peter Kardos, Maingau Hospital, Frankfurt, Germany

Dr Marc Miravitlles, Hospital Clinic, University of Barcelona, Barcelona, Spain

Dr Stephan Molitor, University of Hanover, Hanover, Germany

Professor David Price, University of Aberdeen, Aberdeen, UK

Nicolas Roche, University of Paris 5, Paris, France

Professor Thys van der Molen, University Medical Center Groningen, Groningen,

The Netherlands

\section{Conflict of interest declarations}

PJ has received fees from pharmaceutical companies, including GlaxoSmithKline, for speaking at meetings and participating in advisory board meetings and has received support for research from GlaxoSmithKline.

$\mathrm{GH}$ and NL are employed by the United BioSource Corporation (UBC), which provides consulting and other research services to pharmaceutical, device, government and non-government organizations. In these salaried positions, GH and NL work with a variety of companies and organisations and receive no payment or honoraria directly from these organisations for services rendered. IW and PB are GlaxoSmithKline employees.

\section{References}

1. WHO. COPD: Burden. World Health Organization [Online] http://www.who.int/respiratory/copd/burden/en/index.html

2. National Center for Health Statistics, National Health Interview Survey, 1982-1996, 1997-2002. Information cited in: American Lung Association, Epidemiology and Statistics Unit. Trends in Chronic Bronchitis and Emphysema: Morbidity and Mortality. April 2004

3. Murray CJ, Lopez AD. Alternative projections of mortality and disability by cause 1990-2020: Global Burden of Disease Study. Lancet 1997;349:1498-504. http://dx.doi.org/10.1016/\$0140-6736(96)07492-2

4. Global Initiative for Chronic Obstructive Lung Disease. Global strategy for the diagnosis, management, and prevention of chronic obstructive pulmonary disease. 2007:1-30. http://www.goldcopd.com/GuidelinesResources.asp

5. Standards for the diagnosis and care of patients with chronic obstructive pulmonary disease: American Thoracic Society. Am J Respir Crit Care Med 1995;152 Suppl;S77-121.

6. Siafakas NM, Vermeire P, Price NB, et al. Optimal assessment and management of chronic obstructive pulmonary disease (COPD): The European Respiratory
Society Task Force. Eur Respir J 1995;8:1398-420.

7. Mannino DM, Homa DM, Akinbami $L$, et al. Chronic Obstructive Pulmonary Disease Surveillance-United States, 1971-2000. MMWR Surveill Summ 2002;51(6):1-16. U.S. Department of Health and Human Services, Atlanta, GA 30333, Centers for Disease Control and Prevention.

8. American Association for Respiratory Care. Confronting COPD in America: Executive Summary. http://www.aarc.org/resources/confronting_ copd/exesum.pdf

9. Rennard S, Decramer M, Calverley PMS, et al. Impact of COPD in North America and Europe in 2000: subjects' perspective of Confronting COPD International Survey. Eur Respir J 2002;20:799-805. http://dx.doi.org/10.1183/ 09031936.02 .03242002

10. Celli BR, MacNee W. Standards for the diagnosis and treatment of patients with COPD: a summary of the ATS/ERS position paper. Eur Respir J 2004;23:932-46. http://dx.doi.org/10.1183/09031936.04.00014304

11. Jansson SA, Andersson F, Borg S, et al. Costs of COPD in Sweden according to disease severity. Chest 2002;122(6):1994-2002. http://dx.doi.org/10.1378/ chest.122.6.1994

12. Jones PW, Quirk FH, Baveystock CM. The St George's Respiratory Questionnaire. Respir Med 1991;85 Suppl B:25-31; discussion 3-7.

13. Larson JL, Covey MK, Berry JK, et al. Reliability and validity of the Chronic Respiratory Disease Questionnaire. Am Rev Respir Dis 1993;147:A530.

14. van der Molen T, Willemse BW, et al. Development, validity and responsiveness of the Clinical COPD Questionnaire. Health Qual Life Outcomes 2003;1:13. http://dx.doi.org/10.1186/1477-7525-1-13

15. Bailey WC, Sciurba FC, Hanania NA, et al. Development and validation of the Chronic Obstructive Pulmonary Disease Assessment Questionnaire (COPD-AQ). Prim Care Resp J 2009;18(3):198-207. http://dx.doi.org/10.4104/ pcrj.2009.00032

16. Nathan RA, Sorkness CA, Kosinski M, et al. Development of the asthma control test: a survey for assessing asthma control. I Allergy Clin Immunol 2004;113:59-65. http://dx.doi.org/10.1016/j.jaci.2003.09.008

17. BTS guidelines for the management of chronic obstructive pulmonary disease: The COPD Guidelines Group of the Standards of Care Committee of the BTS. Thorax 1997;52 Suppl 5:S1-28.

18. National Institute for Health and Clinical Excellence (NICE). Clinical Guidelines for Chronic Obstructive Pulmonary Disease. http://www.nice.org.uk/ Guidance/CG12

19. Miravitlles $M$, Anzueto $A$, Legnani $D$, et al. Patient's perception of exacerbations of COPD—the PERCEIVE study. Respir Med 2007;101:453-60. http://dx.doi.org/10.1016/j.rmed.2006.07.010

20. Cazzola M, MacNee W, Martinez FJ, et al. Outcomes for COPD pharmacological trials: from lung function to biomarkers. Eur Respir J 2008;31(2):416-69. http://dx.doi.org/10.1183/09031936.00099306

21. Food and Drug Administration (FDA). Guidance for Industry, Patient-Reported Outcomes Measures: Use in Medical Product Development to Support Labeling Claims. http://www.fda.gov/cder/guidance/index.htm

22. Commissioning for Quality and Innovation Scheme (CQUINS). http://www.dh.gov.uk/en/Publicationsandstatistics/Publications/PublicationsPoli cyAndGuidance/DH_091443 Downloaded 25 February 2009.

\section{Available online at http://www.thepcrj.org}

